\title{
Article \\ Family Perceptions of Newborn Cytomegalovirus Screening: A Qualitative Study
}

\author{
Michael J. Cannon ${ }^{1, \dagger}{ }^{\dagger}$ Denise M. Levis ${ }^{1, \ddagger}$, Holly McBride ${ }^{2}$, Danie Watson ${ }^{3}$, Carol Rheaume ${ }^{3}$, \\ Mary Ann Kirkconnell Hall ${ }^{4}\left(\mathbb{D}\right.$, Tatiana M. Lanzieri ${ }^{5, *}$ and Gail Demmler-Harrison ${ }^{2}$ \\ 1 National Center on Birth Defects and Developmental Disabilities, Centers for Disease Control and Prevention, \\ Atlanta, GA 30333, USA; mrc7@cdc.gov (M.J.C.); DLevis@hrsa.gov (D.M.L.) \\ 2 Department of Pediatrics, Baylor College of Medicine, Houston, TX 77030, USA; \\ hollycorwin@gmail.com (H.M.); gdemmler@bcm.edu (G.D.-H.) \\ 3 Kirby Marketing Solutions, Tampa, FL 33609, USA; dwatson@watsongroupmarketing.com (D.W.); \\ carolerheaume@hotmail.com (C.R.) \\ 4 Eagle Global Scientific for the National Center for Immunization and Respiratory Diseases, \\ Centers for Disease Control and Prevention, Atlanta, GA 30333, USA; nmp8@cdc.gov \\ 5 National Center for Immunization and Respiratory Diseases, Centers for Disease Control and Prevention, \\ Atlanta, GA 30333, USA \\ * Correspondence: tmlanzieri@cdc.gov; Tel.: +1-404-639-3031 \\ + Current affiliation: National Center for Chronic Disease Prevention and Health Promotion, \\ Centers for Disease Control and Prevention, Atlanta, GA 30333, USA. \\ $\ddagger$ Current affiliation: Health Resources \& Services Administration, Rockville, MD 20857, USA.
}

Citation: Cannon, M.J.; Levis, D.M.; McBride, H.; Watson, D.; Rheaume,

C.; Hall, M.A.K.; Lanzieri, T.M.;

Demmler-Harrison, G. Family

Perceptions of Newborn

Cytomegalovirus Screening: A Qualitative Study. Int. J. Neonatal

Screen. 2021, 7, 80. https://doi.org/ $10.3390 /$ ijns7040080

Academic Editor: James B. Gibson

Received: 27 October 2021

Accepted: 16 November 2021

Published: 19 November 2021

Publisher's Note: MDPI stays neutral with regard to jurisdictional claims in published maps and institutional affiliations.

Copyright: (c) 2021 by the authors. Licensee MDPI, Basel, Switzerland. This article is an open access article distributed under the terms and conditions of the Creative Commons Attribution (CC BY) license (https:// creativecommons.org/licenses/by/ $4.0 /)$.
Abstract: We sought to understand long-term retrospective parental perceptions of the utility of newborn screening in a context where many affected children never develop sequelae but where intensive support services and ongoing healthcare were provided. We conducted focus groups and interviews among parents $(\mathrm{N}=41)$ of children with congenital CMV who had been enrolled in a long-term follow-up study at a large medical college for a mean of 22 years following diagnosis. Groups included parents whose children were: symptomatic at birth; initially asymptomatic but later developed sensorineural hearing loss; and who remained asymptomatic into adulthood. With proper follow-up support, newborn CMV screening was viewed positively by parents, who felt empowered by the knowledge, though parents often felt that they and healthcare providers needed more information on congenital CMV. Parents in all groups valued newborn CMV screening in the long term and believed it should be embedded within a comprehensive follow-up program. Despite initial distress, parents of CMV-positive children felt newborn CMV screening was a net positive. Mandatory or opt-out screening for conditions with variable presentations and treatment outcomes may be valuable in contexts where follow-up and care are readily available.

Keywords: congenital cytomegalovirus; newborn screening; parental perceptions; qualitative study

\section{Introduction}

Congenital cytomegalovirus (cCMV) infection occurs in 4.5 per 1000 live births in the United States and is a major cause of birth defects and developmental disabilities, including hearing loss and intellectual disability [1]. Some babies with cCMV infection exhibit symptoms at birth; others develop symptoms during childhood, but most-approximately $80 \%$-never develop any symptoms [2]. Approximately 4000 US children each year develop disabilities due to cCMV infection. Symptomatic children may derive limited benefit from antiviral medications [3]. Initially asymptomatic children may benefit from early detection and intervention for hearing loss [4].

Newborn CMV screening is not part of the current recommended uniform panel [5,6]. Because most CMV-positive newborns never develop the disease, the utility of newborn CMV screening is likely to be especially sensitive to parental acceptability and psychosocial 
harms [7-12]. Parental attitudes have been assessed in hypothetical scenarios [13,14], but not among parents whose children were actually screened for cCMV in the real world. In this study, we assessed perceptions of the utility and acceptability of newborn CMV screening among parents of children who screened CMV positive or were diagnosed with cCMV and were followed through adolescence.

\section{Methods}

In September 2013, we conducted focus groups and interviews with parents of children with cCMV enrolled in a longitudinal study at a large medical college, hereafter referred to as the CMV Study. Children in the CMV Study participated in regular follow-up assessments at 4-6 weeks, 4-6 months, 9-12 months, 18-24 months, approximately yearly through elementary school, and then every 2-3 years through high school. Parents had regular consultations with cCMV experts. For children who were asymptomatic at birth, follow-up monitoring and evaluation in the CMV study were much more frequent and intensive than would be expected outside a research setting [15].

We recruited parents from three groups, defined by their child's health outcomes at birth and during follow-up, and our study included a convenience sample of parents of children with cCMV enrolled in the CMV Study who agreed to participate in focus groups or interviews (Table 1). The Symptomatic Group consisted of 11 parents whose child was born symptomatic; all these children were identified through referrals rather than screening, and typically presented with hearing loss or intellectual disability. The Asymptomatic Late Sequelae Group consisted of nine parents whose child was born asymptomatic but who subsequently developed sequelae (typically sensorineural hearing loss). The Asymptomatic Group consisted of 19 parents whose child was born asymptomatic and who never developed disease sequelae.

Table 1. Description of parent groups and types of information collection.

\begin{tabular}{cccc}
\hline & Asymptomatic Group & $\begin{array}{c}\text { Asymptomatic Late } \\
\text { Sequelae Group }\end{array}$ & $\begin{array}{c}\text { Symptomatic } \\
\text { Group }\end{array}$ \\
\hline $\begin{array}{c}\text { Child health outcomes } \\
\text { Birth }\end{array}$ & Asymptomatic & Asymptomatic & Symptomatic \\
Childhood & Asymptomatic & Symptomatic & Symptomatic \\
Qualitative method & 2 & 7 & 7 \\
One-on-one interview & 1 & 2 & 2 \\
Dyad interview & 3 & 0 & 0 \\
Focus group & $(4,5, \& 6$ parents each) & 11 & 11 \\
Total parents & 19 & & \\
\hline
\end{tabular}

Focus group and interview questions were similar across all three parent groups, though questions were modified to reflect experiences with disease sequelae in the Symptomatic and Asymptomatic Late Sequelae Groups. Questions included how parents felt when they received the positive newborn screen for CMV, probing on potential family and financial stressors; information needs after receiving the positive screen; benefits and challenges from receiving a positive screen; benefits and barriers encountered during the regular follow-up assessments; and opinions about whether and how congenital CMV screening should be offered to parents of newborns.

Two trained and experienced moderators facilitated all focus groups and in-depth interviews. All focus groups and most interviews were conducted in person; four interviews were conducted by phone. Focus groups lasted about $120 \mathrm{~min}$ and interviews lasted about $90 \mathrm{~min}$. All focus groups and interviews were recorded, professionally transcribed, verified for accuracy, and imported into QSR NVivo@ qualitative data analysis software. This research was approved by the institutional review board of the medical college affiliated with the CMV Study, and parents provided oral consent prior to participation. 
Each transcript was thematically coded by two coders using inductive and deductive strategies to identify emergent themes. One coder was the focus group or interview moderator and the other was a researcher experienced with qualitative analysis who had not participated in the focus groups or interviews. The coding team assessed the newborn screening literature in order to situate the data within the larger context of the literature, and to check for possible coder biases by using other sources to verify categories and themes (Appendix A) [16] Coders regularly met to review and compare coding categories (Appendix B) to identify and resolve coding discrepancies, and modify definitions of thematic codes. The analysis examined similarities and differences in themes across parent groups.

\section{Results}

At the time of participants' interview, children were a mean 23 years old (SD = 5.2) and had spent 22 years $(\mathrm{SD}=3.7)$ in the CMV Study. While most participants were the mothers $(77 \%)$, fathers, stepparents, and one grandmother also participated. Their education level varied, with $48 \%$ having college or graduate degrees.

\subsection{Attitudes about Newborn CMV Screening}

Parents in all groups valued newborn CMV screening and subsequent follow-up assessments, although reasons varied slightly across groups (Table 2). Knowing their child's CMV-positive status at birth helped them know what to monitor, who to consult, what to read, and where to look for solutions to current or potential problems.

Table 2. Parents' Attitudes about Newborn CMV Screening.

\begin{tabular}{|c|c|c|c|}
\hline $\begin{array}{l}\text { Parents' Attitudes about Newborn } \\
\text { CMV Screening }\end{array}$ & Asymptomatic Group & $\begin{array}{l}\text { Asymptomatic Late } \\
\text { Sequelae Group }\end{array}$ & Symptomatic Group \\
\hline \multicolumn{4}{|l|}{ Positive Values of CMV Screening } \\
\hline I would do it again because knowledge is power. & $x$ & $x$ & $x$ \\
\hline $\begin{array}{l}\text { It should be routine, especially for prevention for } \\
\text { pregnant women. }\end{array}$ & $x$ & $x$ & $x$ \\
\hline We can treat early and improve your child's life. & $x$ & $x$ & \\
\hline $\begin{array}{l}\text { Test and the foreknowledge it provides are worth } \\
\text { the stress at hearing news "no parent wants to hear." }\end{array}$ & & & $x$ \\
\hline $\begin{array}{l}\text { Avoids a diagnostic odyssey, helps you move into } \\
\text { solutions and action planning quickly. }\end{array}$ & & $x$ & \\
\hline Spare other parents the agony we went through. & & & $x$ \\
\hline $\begin{array}{l}\text { If positive, we'll monitor your kid for health } \\
\text { problems (caveat: if you have access to a program). }\end{array}$ & $x$ & $x$ & \\
\hline $\begin{array}{l}\text { Diagnosis made sure my child got services at school, } \\
\text { college, and medically. Even disability } \\
\text { accommodations for college testing. }\end{array}$ & & $x$ & \\
\hline \multicolumn{4}{|l|}{ Negative Values of CMV Screening } \\
\hline $\begin{array}{l}\text { Anxiety provoking when the proportion of children } \\
\text { who develop problems is so small. }\end{array}$ & $x$ & & \\
\hline $\begin{array}{l}\text { Confusion between value of CMV tests and 3-month } \\
\text { hearing test. }\end{array}$ & $x$ & & \\
\hline \multicolumn{4}{|l|}{ Value of Follow-Up Testing } \\
\hline $\begin{array}{l}\text { Helps you become a better parent by understanding } \\
\text { child development milestones. }\end{array}$ & $x$ & $x$ & $x$ \\
\hline
\end{tabular}


Table 2. Cont.

\section{Parents' Attitudes about Newborn CMV Screening}

\begin{tabular}{|c|c|c|c|}
\hline $\begin{array}{l}\text { Helps parents be more attentive to possible learning } \\
\text { or hearing disabilities and to address them as early } \\
\text { as possible, helping your child to succeed in life. }\end{array}$ & $x$ & $X$ & $x$ \\
\hline $\begin{array}{l}\text { Provides benchmarks for measuring progress, } \\
\text { stabilization, or deterioration of child's condition. }\end{array}$ & & $x$ & $x$ \\
\hline $\begin{array}{l}\text { Permits early intervention for child development, } \\
\text { language development, and hearing loss remedies. }\end{array}$ & & $x$ & $X$ \\
\hline
\end{tabular}

\section{Screening Options}

\begin{tabular}{l}
$\begin{array}{c}\text { If testing were routine, more babies would get tested } \\
\text { and more babies would get help, provided a } \\
\text { program is available. }\end{array}$ \\
$\begin{array}{l}\text { Make mandatory but parent should have the right to } \\
\text { opt out of passive consent if they do not want their } \\
\text { child to be tested. }\end{array}$ \\
$\begin{array}{c}\text { Mandatory testing should occur because innocent } \\
\text { children are at risk. }\end{array}$ \\
\hline Mandatory testing should occur for early \\
intervention before it's too late for the child's health.
\end{tabular}

Xs indicate attitudes expressed by parent groups.

When asked if they were glad that their child had been screened for cCMV, the majority of Asymptomatic Group parents responded, "Yes ... in the long run", or similarly. Most commented that the CMV screening result shocked them and provoked anxiety, especially from uncertainty about the disease and its prognosis, yet they valued the knowledge. One parent simply stated, "Not knowing the truth doesn't make it not true". They valued the CMV Study follow-up assessments because they provided regular monitoring of their child.

Asymptomatic Late Sequelae Group parents expressed no negative views about CMV screening and commonly described the newborn screening as "priceless" and "invaluable". Some recalled that at the time of diagnosis, they were grieved by "news no parent wants to hear," but quickly realized the value of the cCMV diagnosis and the benefit to their child and themselves. It empowered them to know what was happening with their child and be better informed to make decisions and take actions to make their child's life better. Without the cCMV diagnosis, they felt they could have faced a costly, lengthy, and emotional "diagnostic odyssey" to identify the cause of their child's issues. Many parents could not imagine any reason why a parent would not want their newborn screened: "I cannot think of a downside of knowing".

Symptomatic Group parents valued CMV screening as a tool to quickly identify the cause of the symptoms, know how to help their child, learn other symptoms to anticipate, and plan for the future. Though their children's diagnosis was made following testing for cCMV based on clinical suspicion rather than from newborn screening, they too expressed no negative views of newborn screening and, despite the stress of receiving the initial diagnosis, felt it was "absolutely worth it" to know. For instance, one said, "Oh gosh, I think it's invaluable. It's priceless. It's given us so many answers that we wouldn't have known otherwise and so much information to arm ourselves with as we raise him". Another parent said, "It was a blessing that they did that [ . . ] screening that I ... knew nothing about, because from the get-go we had a support group, we had a road map, we had help".

Focus group participants were presented with three scenarios for newborn CMV screening: mandatory screening; opt-out screening, where parents have to actively request not to have their child screened; and opt-in screening, where parents have to actively 
request to have their child screened. Most parents in all groups preferred mandatory screening, with three overarching themes: (1) cCMV is a dangerous infection; (2) early intervention is essential to improve health and developmental outcomes when a newborn tests positive; and (3) withholding this information from parents is wrong when cCMV can be so devastating to children and their families. However, opinions differed somewhat across the groups, with some seeing advantages to the opt-out or opt-in approaches.

Overall, most Asymptomatic Group parents were in favor of mandatory CMV screening. Concerns among Asymptomatic Group parents about mandatory screening included parents' rights, state regulations, government interference and "nanny states", as well as doing what is right for vulnerable groups and protecting pregnant women. Some parents raised the concern that mandatory screening would cause unneeded anxiety, given that the risk of sequelae is low for asymptomatic children. The few parents who supported the opt-out option believed that states should not tell families what to do and preferred that parents make the final choice about screening. Several parents also stipulated that screening should be done only if follow-up assessments and a treatment program, such as the CMV Study, could be offered.

Asymptomatic Late Sequelae Group parents were overwhelmingly in favor of mandatory screening because it would mean more babies would be tested and receive the help they needed. They preferred opt-out screening because many tests are already being performed at birth; seeking consent for a single test just after birth seemed like an imposition at a time when parents are already overwhelmed. They believed more babies would be tested and helped if parents had to actively opt out of screening.

Parents in the Symptomatic Group also overwhelmingly supported mandatory screening, expressing that early detection and intervention were essential to secure the best outcomes for children. One said that mandatory screening was justifiable because, "Number one, it's noninvasive and, number two, there are treatments available for it, and there are options for the family". The few Symptomatic Group parents who did not support mandatory screening were "not really big on government mandates" in general; however, these same parents felt that the benefits of newborn CMV screening outweighed drawbacks. Otherwise, the diagnosis or proper treatment of a vulnerable child could be delayed. During these discussions, many parents expressed distress about their lack of awareness about cCMV and that they had not been given a chance to prevent the infection in their child. Symptomatic Group parents spoke frequently about how mandatory screening could raise awareness about cCMV and how to prevent infection during pregnancy, thus protecting future parents and children from the "agony of what we went through".

\subsection{Impact of Receiving Initial CMV Test Results}

The tone of parents' emotional reactions to receiving the news of the CMV test results varied, but almost all reactions were negative (Table 3).

Many Asymptomatic Group parents discussed feeling unhappy and depressed about a baby who might develop significant health issues in the future. Many took months, or even years, to adjust to the cCMV diagnosis. Asymptomatic Late Sequelae Group parents reported feeling scared by the news of a disease they had never heard of. One mother said, "I was like, oh my gosh, this could be a lifelong challenge, this could be a game-changer for sure".

Some Symptomatic Group parents also reported feeling emotional turmoil. One parent said, "I guess the age-old question is, 'Why me?' For the first couple of months, I blamed myself, my husband blamed himself". Another said, "I was having emotional distress because of the fact that my child wasn't 'normal'". Several mentioned that they received the initial test results just hours after giving birth, and because of their children's acute symptoms, these parents were often isolated from their newborns just as these worries surfaced. 
Table 3. Psychosocial Impacts on Parents.

\begin{tabular}{|c|c|c|c|}
\hline Psychosocial Impacts on Parents & Asymptomatic Group & $\begin{array}{l}\text { Asymptomatic Late } \\
\text { Sequelae Group }\end{array}$ & Symptomatic Group \\
\hline \multicolumn{4}{|l|}{ Concerns about CMV Child's Development } \\
\hline \multicolumn{4}{|l|}{ Positive Impact } \\
\hline Pride in affected child's attitude and successes & $X$ & $X$ & \\
\hline Felt calmer or less scared & $x$ & $x$ & \\
\hline Felt well informed about risks & & $x$ & \\
\hline $\begin{array}{l}\text { Calmed by good medical advice and treatment } \\
\text { programs }\end{array}$ & & $x$ & \\
\hline Little or no fear for child's future well being & & $x$ & \\
\hline Pride in meeting the challenges & & $x$ & \\
\hline No major positive impacts & & & $x$ \\
\hline \multicolumn{4}{|l|}{ Negative Impact } \\
\hline Felt scared or panicky & $x$ & $x$ & \\
\hline Fear for child's future well being & & $X$ & $\mathrm{X}$ \\
\hline Fear for child's future health & & & $x$ \\
\hline \multicolumn{4}{|l|}{$\begin{array}{c}\text { Concerns about Child's Future Physical } \\
\text { Health Development }\end{array}$} \\
\hline Positive Impact & & None & \\
\hline Felt well informed about risks & $\mathrm{x}$ & & \\
\hline Calmed by good medical advice & $x$ & & \\
\hline Felt calmer or less scared & & & $\mathrm{x}$ \\
\hline \multicolumn{4}{|l|}{ Negative Impact } \\
\hline Fear for child's future health & $\mathrm{X}$ & $X$ & $X$ \\
\hline Felt scared or panicky & $x$ & $x$ & \\
\hline Felt under strain & & & $x$ \\
\hline \multicolumn{4}{|l|}{$\begin{array}{l}\text { Concerns about Managing the Educational } \\
\text { System in Relation to Their CMV Child }\end{array}$} \\
\hline Positive Impact & None & None & None \\
\hline Negative Impact & None & & \\
\hline $\begin{array}{l}\text { Concerns about how child would be accepted by } \\
\text { family and friends }\end{array}$ & & $x$ & \\
\hline Felt under strain & & & $\mathrm{X}$ \\
\hline \multicolumn{4}{|l|}{ Emotion of Receiving Initial CMV Test Results } \\
\hline Positive Impact & None & None & None \\
\hline \multicolumn{4}{|l|}{ Negative Impact } \\
\hline Felt scared or panicky & $x$ & $x$ & \\
\hline Felt unhappy and depressed & $x$ & & \\
\hline Felt under strain & & & $X$ \\
\hline \multicolumn{4}{|l|}{ Employment Issues Related to CMV Child } \\
\hline Positive Impact & None & None & None \\
\hline Negative Impact & None & None & \\
\hline Felt under strain & & & $x$ \\
\hline
\end{tabular}


Table 3. Cont.

\begin{tabular}{|c|c|c|c|}
\hline Psychosocial Impacts on Parents & Asymptomatic Group & $\begin{array}{l}\text { Asymptomatic Late } \\
\text { Sequelae Group }\end{array}$ & Symptomatic Group \\
\hline \multicolumn{4}{|l|}{ Family Issues } \\
\hline \multicolumn{4}{|l|}{ Positive Impact } \\
\hline $\begin{array}{l}\text { Improved social supports, both tangible and } \\
\text { intangible }\end{array}$ & $x$ & $x$ & $x$ \\
\hline $\begin{array}{l}\text { Unconcerned or little concern about how child } \\
\text { would be accepted by family and friends }\end{array}$ & & $x$ & \\
\hline Felt calmer or less scared & & $X$ & \\
\hline Negative Impact & & None & \\
\hline Perceived reduced intangible social support & $x$ & & \\
\hline Had strained relationships with family and friends & & & $X$ \\
\hline Felt under strain & $\mathrm{X}$ & & \\
\hline \multicolumn{4}{|l|}{ Financial Issues } \\
\hline \multicolumn{4}{|l|}{ Positive Impact } \\
\hline $\begin{array}{l}\text { Unconcerned or little concern about healthcare } \\
\text { costs of tests and treatments, if needed }\end{array}$ & $x$ & $x$ & \\
\hline Felt calmer or less scared & & $x$ & $x$ \\
\hline Negative Impact & & None & \\
\hline $\begin{array}{c}\text { Concern about healthcare costs of tests and } \\
\text { treatments, if needed }\end{array}$ & $x$ & & $x$ \\
\hline \multicolumn{4}{|l|}{ Friends and Their Social Support } \\
\hline Positive Impact & None & None & None \\
\hline Negative Impact & None & None & None \\
\hline \multicolumn{4}{|l|}{ Marital Concerns and Issues } \\
\hline \multicolumn{4}{|l|}{ Positive Impact } \\
\hline Improved relationships & $x$ & $x$ & $x$ \\
\hline Negative Impact & None & None & None \\
\hline \multicolumn{4}{|l|}{ CMV Medical Assistance and Testing Programs } \\
\hline \multicolumn{4}{|l|}{ Positive Impact } \\
\hline Caring medical practice or system & $x$ & $x$ & $x$ \\
\hline $\begin{array}{l}\text { Felt reassured by good medical advice, } \\
\text { treatment programs }\end{array}$ & $x$ & $x$ & $x$ \\
\hline Felt well informed about risks & $x$ & & \\
\hline Felt happy and encouraged & $x$ & & \\
\hline Felt calmer or less scared & $x$ & & \\
\hline $\begin{array}{l}\text { Unconcerned or little concern about healthcare } \\
\text { costs of tests and treatments, if needed }\end{array}$ & & $x$ & \\
\hline Negative Impact & & None & \\
\hline Concerns about unnecessary medical visits & $x$ & & \\
\hline $\begin{array}{l}\text { Impersonal or uncaring medical practice or system } \\
\text { (isolated and infrequent) }\end{array}$ & & & $x$ \\
\hline
\end{tabular}


Table 3. Cont.

\begin{tabular}{|c|c|c|c|}
\hline Psychosocial Impacts on Parents & Asymptomatic Group & $\begin{array}{l}\text { Asymptomatic Late } \\
\text { Sequelae Group }\end{array}$ & Symptomatic Group \\
\hline \multicolumn{4}{|l|}{$\begin{array}{l}\text { Medical Practitioners and Systems Related to } \\
\text { CMV Child }\end{array}$} \\
\hline Positive Impact & None & None & None \\
\hline \multicolumn{4}{|l|}{ Negative Impact } \\
\hline $\begin{array}{l}\text { Felt anger (or dissatisfaction) at poor medical } \\
\text { advice outside CMV Program }\end{array}$ & $x$ & $X$ & $\mathrm{X}$ \\
\hline \multicolumn{4}{|l|}{ Parenting Skills } \\
\hline Positive Impact & None & & \\
\hline $\begin{array}{l}\text { Feeling clear about what would be best for my } \\
\text { child }\end{array}$ & & $x$ & \\
\hline Pride in meeting the challenges & & & $x$ \\
\hline Negative Impact & None & None & \\
\hline Concerns about properly caring for the child & & & $x$ \\
\hline \multicolumn{4}{|l|}{$\begin{array}{l}\text { Parent-Child Relationship Related to } \\
\text { CMV Child }\end{array}$} \\
\hline Positive Impact & & & None \\
\hline $\begin{array}{l}\text { Unconcerned or little concern about parenting and } \\
\text { parent-child bond }\end{array}$ & $x$ & $x$ & \\
\hline Negative Impact & None & None & None \\
\hline
\end{tabular}

Xs indicate psychosocial impact expressed by parent groups. None indicates that psychosocial impact was not expressed by parent groups.

Parents in both the Asymptomatic Late Sequelae Group and the Symptomatic Group recalled having many questions about $\mathrm{CCMV}$ and felt frustrated when medical professionals did not have answers. Parents whose children were identified through referrals reported initially receiving poor medical information about cCMV. By contrast, parents whose children were identified through screening said that the high-quality medical advice they received calmed their fears.

\subsection{Impact on Parents of Knowing Their Child Had cCMV}

Parents spoke of their knowledge as two sides of the same coin, recalling that it promoted ongoing observation (as part of the CMV Study and at home) and a better understanding of their child's development, as well as worry about their child's uncertain future.

Among Asymptomatic Group parents, uncertainty and fear were prominent. One parent recalled, "It was always the 'what if' in the back of your mind. Is he going to develop? How is he going to do? Is he normal and plays with blocks?" Parents said the uncertainty and fear were strongest and more frequent when their child was an infant. One said, "He would be asleep and I'd sneak up to him and clap real loud to see if he will wake up, and a couple of times he didn't and I would say, 'Oh my God.'"

Asymptomatic Late Sequelae Group parents remembered feeling fear and uncertainty early on. In addition, they described feelings of panic when sequelae surfaced (most commonly hearing loss) and their child's health changed quickly. One parent noted, "I got terrified. The last time he was [at the clinic], everything is fine and looked okay to us. Twelve months later, all his hearing in one ear has gone." Parents reported that access to the CMV Study was "critical" as they navigated the uncertainties of their child's future. They felt that information received through the CMV Study was very helpful as they advocated for their child within the school systems. One parent recalled that knowledge about her daughter's hearing loss helped her convince the teacher to move her child's seat so that she could better hear during class. 
Symptomatic Group parents, whose children were already showing signs of cCMV disease at birth, expressed fear, uncertainty, and sadness about their child's health. For some, the fear manifested as elevated vigilance. One participant described watching his daughter closely for any signs of health issues "to get her a jump on any sort of illness that she had ... this is not a normal child. She does not have the means of communicating. When things go bad, they go bad quickly."

Many Symptomatic Group parents characterized their knowledge about cCMV and access to follow-up assessments as "empowering." Some expressed gratitude for the newborn CMV diagnosis and worried about parents of children with CCMV without a diagnosis: "I wonder how many [parents] out there don't know that their child had congenital CMV, and they just don't know. And they are dealing with all these dilemmas."

For many parents, anxiety and fear were still present during regular follow-up assessments. Overall, however, they reported that they were better able to navigate the complexities of cCMV because participating in the CMV Study made them well informed of the potential health and developmental effects of the virus. A parent said, "It prepared me for what could happen. If I hadn't known then, it would've been even more sad."

\section{Discussion}

Our main findings were as follows: (1) positive newborn CMV screening results often caused stress and anxiety, sometimes at high levels, especially during the first notification; (2) stress and anxiety diminished over time; (3) parents were calmed by quality advice and follow-up care; (4) parents valued developmental screening and early interventions; and (5) parents valued newborn CMV screening and felt it should be offered for all newborns.

Overall, parents in all groups were glad their child was screened for (or in the case of the Symptomatic group, tested for) cCMV and supported universal newborn CMV screening. As expected, this support was strong among parents whose children had symptoms at birth or who developed late-onset sequelae. More surprisingly, parents of children who always remained asymptomatic also expressed strong support for newborn CMV screening. This support was reflected in a recent study among adult women, where knowledge levels of cCMV were low, but support for screening was very high when respondents were educated about the condition [14]. Parental attitudes towards screening are complex and change over time, demonstrating the challenges inherent in assessing the utility of newborn screening [17]. For conditions such as CCMV, where treatment benefits are modest and risks apparent, newborn screening with parental consent may be a more logical and ethical approach than mandatory screening $[7,18,19]$.

One potential harm of newborn CMV screening is the risk of adverse effects from medical treatment of asymptomatic or mildly symptomatic infants who would not meet eligibility criteria for antiviral therapy and who would not have been diagnosed in the absence of screening [12]. Other potential harms include psychosocial and logistic burden on families from more frequent clinical evaluations (e.g., for early detection of sensorineural hearing loss), and disparities in access to diagnostic evaluation and antiviral therapy among infants who screen positive [12]. We found that parents whose children were identified through screening found the high-quality medical advice they received reassuring. All parent groups emphasized that appropriate education, support, and follow-up are crucial. As noted above, the families in our study had access to frequent follow-up and specialized care from physicians trained to work with children with $\mathrm{CCMV}$, which were typically funded by the CMV study. This support, which parents considered pivotal to their children's development and their own psychosocial adjustment, may be difficult to replicate outside of research settings. Thus, the experience of parents in our study cannot be generalized to that of parents whose children might be diagnosed with CCMV as part of a future newborn screening program.

Our study has important limitations. By virtue of their willingness to participate in the study, parents were likely to be more highly motivated to seek out answers and support, and accordingly be in favor of universal or opt-in testing, than members of the general 
public might be. Participants tended to be highly educated; it is unclear how results might have differed for parents with lower education levels. Another limitation of our study was the opportunity for recall bias, as parents described events that occurred years and even decades previously. However, participants had a long-term perspective to draw upon, which might have given them a more holistic view of the value of newborn CMV screening. Remarks made by this cohort of parents, specifically reactions to potential hearing loss or disability in general, may be bound somewhat by the time period in which the original screening and medical follow-ups were completed. Parental reactions to screening results and possible disability status, specifically hearing loss, may be different now as knowledge about interventions has changed over time. Finally, we did not interview parents whose children screened negative for CCMV.

Parents who were informed and whose children received supportive monitoring were strongly in favor of universal newborn CMV screening, even those whose children never developed disease sequelae. However, screening can introduce stress and anxiety among parents, especially immediately after diagnosis, a particular concern for cCMV since many children who screen positive will never experience disease sequelae, and possibly for other conditions in which disease manifestations may be extremely delayed in onset and variable in intensity. Such findings raise important considerations for policy deliberations about newborn CMV screening and the design of future screening programs, including systems for long-term follow-up and monitoring of children identified with cCMV as well as for support for their families.

Author Contributions: M.J.C. conceptualized and designed the study, drafted the initial manuscript, and reviewed the manuscript. D.M.L. carried out the initial analyses and reviewed the manuscript. H.M. collected data, coordinated and supervised data collection, carried out the initial analyses, and reviewed the manuscript. D.W. and C.R. designed the data collection instruments, collected data, carried out the initial analyses, and reviewed the manuscript. M.A.K.H. and T.M.L. participated in the literature review, context analysis and interpretation of findings, and extensively revised the manuscript for intellectual content and methodology. G.D.-H. conceptualized and designed the study and reviewed the manuscript. All authors have read and agreed to the published version of the manuscript.

Funding: This work was supported by the Centers for Disease Control and Prevention [cooperative agreement FOA IP 10-006].

Institutional Review Board Statement: The study was conducted according to the guidelines of the Declaration of Helsinki and approved by the Institutional Review Board of Baylor College of Medicine, the medical college affiliated with the CMV Study (Protocol number H-30776, date of initial approval: 5 December 2012).

Informed Consent Statement: Parents provided oral consent prior to participation in the focus groups and interviews for this study.

Data Availability Statement: The data presented in this study are available on request from the corresponding author Tatiana M. Lanzieri (tmlanzieri@cdc.gov). The data are not publicly available due to privacy restrictions.

Acknowledgments: We thank all the family members who participated in the focus groups and interviews in this study, and Susan Kirby (In Memoriam) for her contribution to the development of this study. We also thank all children who participated in the CMV study, their families and physicians for their lifetime of dedication and support for the CMV study.

Conflicts of Interest: The authors have no conflict of interest relevant to this article to disclose. The authors have no financial relationships relevant to this article to disclose. The findings and conclusions in this article are those of the authors and do not necessarily represent the official position of the Centers for Disease Control and Prevention. 


\section{Appendix A}

Table A1. Categories of Psychosocial Impacts Identified in Literature Review.

\begin{tabular}{|c|c|c|}
\hline & $\begin{array}{l}\text { Literature Review Summary } \\
\text { Categories of Psychosocial Impacts }\end{array}$ & \# of Mentions \\
\hline $\begin{array}{l}1 . \\
2 .\end{array}$ & $\begin{array}{l}\text { Felt nervous or strung up } \\
\text { Felt scared or panicky }\end{array}$ & 21 \\
\hline 3. & Concern about healthcare costs of initial test, follow up tests, and future treatment, if needed & 11 \\
\hline 4. & Improved social support, both tangible and intangible & 9 \\
\hline 5. & Concerns about properly caring for child & 8 \\
\hline 6. & Anger from not knowing risks & 6 \\
\hline 7. & Felt unhappy and depressed & 7 \\
\hline 8. & Fear for child's future health & 8 \\
\hline $\begin{array}{l}9 . \\
10 .\end{array}$ & $\begin{array}{l}\text { Felt others were to blame for child's health issues } \\
\text { Felt I was to blame for child's health problems }\end{array}$ & 6 \\
\hline 11. & Concerns about parenting and parent-child bond & 6 \\
\hline $\begin{array}{l}12 . \\
13 .\end{array}$ & $\begin{array}{l}\text { Felt worried about the future } \\
\text { Fear for child's future well being }\end{array}$ & 5 \\
\hline 14. & Concerns about how child will be accepted by family and friends & 5 \\
\hline 15. & Concern about unnecessary medical visits & 5 \\
\hline $\begin{array}{l}16 . \\
17 .\end{array}$ & $\begin{array}{l}\text { A greater sense of well being } \\
\text { Pride in meeting the challenges }\end{array}$ & 4 \\
\hline 18. & Pride in affected child's attitude and successes & 4 \\
\hline 19. & Anger at poor medical advice & 4 \\
\hline 20. & Feeling confused about what will be best for my child & 3 \\
\hline 21. & Fear of treatment procedures for my child & 2 \\
\hline $\begin{array}{l}22 . \\
23 .\end{array}$ & $\begin{array}{l}\text { Improved relationships with friends or family } \\
\text { Getting on better with those around you }\end{array}$ & 2 \\
\hline 24. & Guilt over not taking preventative actions or not knowing about preventative actions. & 2 \\
\hline & $\begin{array}{l}\text { Concern that medical professionals don't explain things well } \\
\text { Feeling confused about medical advice }\end{array}$ & 2 \\
\hline 27. & Hopeful about the future & 2 \\
\hline & Fear of future parenthood & 2 \\
\hline 29. & Felt under strain & 1 \\
\hline 30. & Felt stress to heavily research the health issues through family, friends, books, and Internet & 1 \\
\hline
\end{tabular}

Experienced researchers coded for specific psychosocial impacts that were identified in the literature review, which resulted in 155 codes entered into a database. Similar or nearly similar concepts and ideas were grouped together resulting in a total of 30 relatively unique impacts. Because these 30 codes were a combination of positive and negative impacts, we 
created corollaries for each code so that each negative impact had a positive impact in case a parent expressed the opposite feeling during the focus groups or interviews. The final table of coded negative and positive impacts can be found in Appendix B (Table 2).

\section{Appendix B}

Table 2. Corollaries of Negative and Positive Impacts.

\begin{tabular}{|c|c|}
\hline Negative Impact & Positive Impact \\
\hline Anger (or dissatisfaction) at poor medical advice & Calmed by good medical advice, treatment programs \\
\hline Anger (or dissatisfaction) from not knowing risks & Felt well informed about risks \\
\hline $\begin{array}{l}\text { Felt scared or panicky or } \\
\text { Felt nervous or strung up }\end{array}$ & Felt calmer or less scared (often due to help from medical advice) \\
\hline Felt unhappy and depressed & Felt happy and encouraged \\
\hline Concern about being unaware of disease ${ }^{*}$ & Unconcerned or little concern about being unaware of disease \\
\hline $\begin{array}{l}\text { Concern about healthcare costs of tests and treatments, } \\
\text { if needed }\end{array}$ & $\begin{array}{c}\text { Unconcerned or little concern about healthcare costs of tests and } \\
\text { treatments, if needed }\end{array}$ \\
\hline Concern about unnecessary medical visits & Unconcerned or little concern about unnecessary medical visits \\
\hline Concern that medical professionals don't explain things well & $\begin{array}{l}\text { Unconcerned or little concern that medical professionals don't explain } \\
\text { things well }\end{array}$ \\
\hline Concerns about how child will be accepted by family and friends & $\begin{array}{l}\text { Unconcerned or little concern about how child will be accepted by } \\
\text { family and friends }\end{array}$ \\
\hline Concerns about parent-child bond & Unconcerned or little concern about parenting and parent-child bond \\
\hline Concerns about properly caring for child & Unconcerned or little concern about properly caring for child \\
\hline Depressed about the future & Hopeful about the future \\
\hline Dishonor we did not meet the challenges better & Pride in meeting the challenges \\
\hline Fear for child's future health & Little or no fear for child's future health \\
\hline Fear for child's future well being & Little or no fear for child's future well being \\
\hline Fear of future parenthood & Little or no fear of future parenthood \\
\hline Fear of treatment procedures for my child & Little or no fear of treatment procedures for my child \\
\hline Feeling confused about medical advice & Feeling clear about medical advice \\
\hline Feeling confused about what will be best for my child & Feeling clear about what will be best for my child \\
\hline Felt I was to blame for child's health problems & Felt I took good care of myself during my pregnancy \\
\hline Felt nervous or strung up & Felt calm and collected \\
\hline Felt others were to blame for child's health issues & Felt no one was to blame for my child's health problems \\
\hline $\begin{array}{l}\text { Felt stress to heavily research the health issues through family, friends, } \\
\text { books, and Internet }\end{array}$ & Felt confident I was getting good medical information from the doctors \\
\hline Felt under strain & Felt at peace \\
\hline Felt worried about the future & Felt unworried about the future \\
\hline $\begin{array}{c}\text { Guilt over not taking preventative actions or not knowing about } \\
\text { preventative actions. }\end{array}$ & Sense of surety that I took all of the precautions I knew about \\
\hline Having trouble with those around you & Getting on better with those around you \\
\hline Poor sense of well being & Greater sense of well being \\
\hline Reduced social support, intangible & Improved social support just intangible \\
\hline Reduced social support both tangible and intangible & Improved social support both tangible and intangible \\
\hline Sadness about my affected child's attitude and successes & Pride in affected child's attitude and successes \\
\hline Strained relationships with friends and family & Improved relationships with friends or family \\
\hline Impersonal or uncaring medical practice or school system * & Caring medical practice or system \\
\hline $\begin{array}{l}\text { Concerns about multiple locations to visit for healthcare treatments or } \\
\text { logistics of treatment appointments * }\end{array}$ & $\begin{array}{l}\text { Unconcerned or little concern about multiple locations to visit for } \\
\text { healthcare treatments or logistics of treatment appointments }\end{array}$ \\
\hline
\end{tabular}


During the coding of the original research for this project, researchers used the 30 codes identified in the literature review to categorize the psychosocial impacts that parents expressed, and created corollaries for each code so that each negative impact had a positive impact in case a parent expressed the opposite feeling during the focus groups or interviews.

\section{References}

1. Fowler, K.B.; Ross, S.A.; Shimamura, M.; Ahmed, A.; Palmer, A.L.; Michaels, M.G.; Bernstein, D.I.; Sánchez, P.J.; Feja, K.N.; Stewart, A.; et al. Racial and ethnic differences in the prevalence of congenital cytomegalovirus infection. J. Pediatr. 2018, 200, 196-201. [CrossRef]

2. Dollard, S.C.; Grosse, S.; Ross, D.S. New estimates of the prevalence of neurological and sensory sequelae and mortality associated with congenital cytomegalovirus infection. Rev. Med. Virol. 2007, 17, 355-363. [CrossRef]

3. Kimberlin, D.W.; Jester, P.M.; Sánchez, P.J.; Ahmed, A.; Arav-Boger, R.; Michaels, M.G.; Ashouri, N.; Englund, J.A.; Estrada, B.; Jacobs, R.F.; et al. Valganciclovir for symptomatic congenital cytomegalovirus disease. N. Engl. J. Med. 2015, 372, 933-943. [CrossRef]

4. Cannon, M.J.; Griffiths, P.D.; Aston, V.; Rawlinson, W. Universal newborn screening for congenital CMV infection: What is the evidence of potential benefit? Rev. Med. Virol. 2014, 24, 291-307. [CrossRef] [PubMed]

5. Long, S.S.; Brady, M.T.; Jackson, M.A.; Kimberlin, D.W. Red Book 2018: Report of the Committee on Infectious Diseases; American Academy of Pediatrics: Itasca, IL, USA, 2018.

6. Centers for Disease Control and Prevention. Impact of expanded newborn screening-United States, 2006. MMWR Morb. Mortal Wkly. Rep. 2008, 57, 1012-1015.

7. Grosse, S.D.; Dollard, S.; Ross, D.S.; Cannon, M. Newborn screening for congenital cytomegalovirus: Options for hospital-based and public health programs. J. Clin. Virol. 2009, 46 (Suppl. 4), S32-S36. [CrossRef] [PubMed]

8. Beucher, J.; Leray, E.; Deneuville, E.; Roblin, M.; Pin, I.; Bremont, F.; Turck, D.; Giniès, J.-L.; Foucaud, P.; Rault, G.; et al. Psychological effects of false-positive results in cystic fibrosis newborn screening: A two-year follow-up. J. Pediatr. 2010, 156, 771-776. [CrossRef] [PubMed]

9. Lipstein, E.A.; Perrin, J.M.; Waisbren, S.E.; Prosser, L.A. Impact of false-positive newborn metabolic screening results on early health care utilization. Genet. Med. 2009, 11, 716-721. [CrossRef] [PubMed]

10. Prosser, L.A.; Ladapo, J.A.; Rusinak, D.; Waisbren, S.E. Parental tolerance of false-positive newborn screening results. Arch Pediatr. Adolesc. Med. 2008, 162, 870-876. [CrossRef] [PubMed]

11. Waisbren, S.E.; Albers, S.; Amato, S.; Ampola, M.; Brewster, T.G.; Demmer, L.; Eaton, R.B.; Greenstein, R.; Korson, M.; Larson, C.; et al. Effect of expanded newborn screening for biochemical genetic disorders on child outcomes and parental stress. JAMA 2003, 290, 2564-2572. [CrossRef] [PubMed]

12. Goldenberg, A.J.; Comeau, A.M.; Grosse, S.D.; Tanksley, S.; Prosser, L.A.; Ojodu, J.; Botkin, J.R.; Kemper, A.R.; Green, N.S. Evaluating harms in the assessment of net benefit: A framework for newborn screening condition review. Matern. Child Health J. 2016, 20, 693-700. [CrossRef] [PubMed]

13. Din, E.S.; Brown, C.J.; Grosse, S.; Wang, C.; Bialek, S.R.; Ross, D.S.; Cannon, M.J. Attitudes toward newborn screening for cytomegalovirus infection. Pediatrics 2011, 128, e1434-e1442. [CrossRef] [PubMed]

14. Tastad, K.J.; Schleiss, M.R.; Lammert, S.M.; Basta, N.E. Awareness of congenital cytomegalovirus and acceptance of maternal and newborn screening. PLoS ONE 2019, 14, e0221725. [CrossRef] [PubMed]

15. Kadambari, S.; Williams, E.; Luck, S.; Griffiths, P.; Sharland, M. Evidence based management guidelines for the detection and treatment of congenital CMV. Early Hum. Dev. 2011, 87, 723-728. [CrossRef] [PubMed]

16. Lindlof, T.R.; Taylor, B.C. Qualitative Communication Research Methods, 2nd ed.; Sage: Thousand Oaks, CA, USA, 2002.

17. Grosse, S.D.; Boyle, C.A.; Kenneson, A.; Khoury, M.J.; Wilfond, B.S. From public health emergency to public health service: The implications of evolving criteria for newborn screening panels. Pediatrics 2006, 117, 923-929. [CrossRef] [PubMed]

18. Moyer, V.A.; Calonge, N.; Teutsch, S.M.; Botkin, J.R. Expanding newborn screening: Process, policy, and priorities. Hastings Cent. Rep. 2008, 38, 32-39. [CrossRef] [PubMed]

19. Ross, L.F. Mandatory versus voluntary consent for newborn screening? Kennedy Inst. Ethics J. 2010, 20, 299-328. [PubMed] 